\title{
Effect of Annealing on Structural, Morphological, Electrical and Optical Studies of Nickel Oxide Thin Films
}

\author{
Vikas Patil $^{*}$, Shailesh Pawar ${ }^{1}$, Manik Chougule ${ }^{1}$, Prasad Godse ${ }^{1}$, Ratnakar Sakhare ${ }^{1}$, Shashwati Sen ${ }^{2}$, \\ Pradeep Joshi ${ }^{1}$
}

${ }^{1}$ Materials Research Laboratory, School of Physical Sciences, Solapur University, Solapur, India; ${ }^{2}$ Crystal Technology Section, Bhabha atomic Research Centre, Mumbai, India.

Email: drvbpatil@gmail.com

Received March 28 ${ }^{\text {th }}$, 2011; revised May $3^{\text {rd }}$, 2011; accepted May $13^{\text {th }}, 2011$.

\begin{abstract}
Sol gel spin coating method has been successfully employed for the deposition of nanocrystalline nickel oxide (NiO) thin films. The films were annealed at $400^{\circ} \mathrm{C}-700^{\circ} \mathrm{C}$ for $1 \mathrm{~h}$ in an air and changes in the structural, morphological, electrical and optical properties were studied. The structural properties of nickel oxide films were studied by means of $X$-ray diffraction (XRD) and scanning electron microscopy (SEM). XRD analysis shows that all the films are crystallized in the cubic phase and present a random orientation. Surface morphology of the nickel oxide film consists of nanocrystalline grains with uniform coverage of the substrate surface with randomly oriented morphology. The electrical conductivity showed the semiconducting nature with room temperature electrical conductivity increased from $10^{-4}$ to $10^{-2}(\Omega \mathrm{cm})^{-1}$ after annealing. The decrease in the band gap energy from 3.86 to $3.47 \mathrm{eV}$ was observed after annealing $\mathrm{NiO}$ films from $400{ }^{\circ} \mathrm{C}-700^{\circ} \mathrm{C}$. These mean that the optical quality of NiO films is improved by annealing.
\end{abstract}

Keywords: Nickel Oxide, Sol Gel Method, Structural Properties, Optoelectronic Properties

\section{Introduction}

Metal oxides can adopt a large variety of structural geometries with an electronic structure that may exhibit metallic, semiconductor, or insulator characteristics, endowing them with diverse chemical and physical properties. Therefore, metal oxides are the most important functional materials used for chemical and biological sensing and transduction. Moreover, their unique and tunable physical properties have made themselves excellent candidates for electronic and optoelectronic applications. Nanostructured metal oxides have been actively studied due to both scientific interests and potential applications [1,2].

$\mathrm{NiO}$ is an important antifromagnetic p-type semiconductor with excellent properties such as gas-sensing, catalytic and electrochemical properties, and has been studied widely for applications in solid-state sensors, electrochromic devices and heterogeneous catalysts as well as lithium batteries. The nickel oxide thin films have been prepared using various techniques including ther- mal evaporation [3], spray pyrolysis [4], chemical vapor deposition [5], electrochemical deposition [6], sol-gel [7,8], sputtering [9-11], chemical solution deposition [12-16], etc. Among these, chemical solution deposition, also called as a chemical bath deposition, is an advantageous technique due to its low cost, low-temperature operating condition and freedom to deposit materials on a variety of substances. Verkey and Fort [14] deposited nickel oxide thin films using nickel sulfate and ammonia solution over the temperature range 330 - $350 \mathrm{~K}$. Pramanik and Bhattacharya [12] prepared nickel oxide thin films from an aqueous solution composed of nickel sulfate, potassium persulfate, and ammonia atroom temperature. Han et al. [15] studied growth mechanism of nickel oxide thin films following Pramanik's chemistry. Banerjee et al. [16] obtained hexagonal mesoporous nickel oxide using dodecyl sulfate as a surfactant and urea as a hydrolyzing agent.

To the best of our knowledge, few works are available in the literature on the sol-gel synthesis and characterization of NiO-based nanosystems $[7,8]$. 
In the present study, we report new method of synthesis and characterization of nanocrystalline $\mathrm{NiO}$ thin films by simple and inexpensive sol-gel spin coating technique and effect of annealing on their structure, morphology, electric transport and optical properties.

\section{Experimental Details}

Nanocrystalline $\mathrm{NiO}$ thin films have been synthesized by a sol-gel method using Nickel acetate $\mathrm{Ni}\left(\mathrm{CH}_{3} \mathrm{COO}\right)_{2} \cdot 4 \mathrm{H}_{2} \mathrm{O}$ as a source of Ni. In a typical experiment; $3.322 \mathrm{gm}$ of nickel acetate was added to $40 \mathrm{ml}$ of methanol and stirred vigorously at $60^{\circ} \mathrm{C}$ for $1 \mathrm{hr}$, leading to the formation of light green colored powder. The as prepared powder was sintered at various temperatures ranging from 400 $700^{\circ} \mathrm{C}$ with a fixed annealing time of $1 \mathrm{hr}$ in an ambient air to obtain $\mathrm{NiO}$ films with different crystallite sizes. The nanocrystalline $\mathrm{NiO}$ powder was further dissolved in $m$-cresol and solution was continuously stirred for $11 \mathrm{~h}$ at room temperature and filtered. The filtered solution was deposited on to a glass substrate by a single wafer spin processor (APEX Instruments, Kolkata, Model SCU 2007). After setting the substrate on the substrate holder of the spin coater, the coating solution (approximately $0.2 \mathrm{ml}$ ) was dropped and spin-casted at 3000 RPM for 40 $\mathrm{s}$ in an air and dried on a hot plate at $100^{\circ} \mathrm{C}$ for $10 \mathrm{~min}$. Figure 1 shows the flow chart for the sol-gel synthesis of the NiO films prepared by using the spin-coating technique. The structural properties of the films were investigated by means of X-ray diffraction (XRD) (Philips PW-3710, Holland) using $\mathrm{Cu} \mathrm{K} \alpha$ radiation $(\lambda=1.5406$ $\AA$ ). The surface morphology of the films was examined by scanning electron microscopy (SEM) (Model Japan), operated at $20 \mathrm{kV}$. The room temperature dc electrical conductivity measurements were performed using four probe techniques. The optical absorption spectra of the $\mathrm{NiO}$ thin films were measured using a double-beam spectrophotometer Shimadzu UV-140 over 200 - 1000 $\mathrm{nm}$ wavelength range. The thickness of the film was measured by using weight difference method and Dektak profilometer.

\section{Results and Discussion}

\subsection{NiO Film Formation Mechanism and Thickness Measurement}

The mechanism of NiO film formation by the sol gel spin coating method can be enlightened as follows:

$$
\begin{aligned}
& \mathrm{Ni}\left(\mathrm{CH}_{3} \mathrm{COO}\right)_{2} \cdot 4 \mathrm{H}_{2} \mathrm{O}+2 \mathrm{CH}_{3}-\mathrm{OH} \rightarrow \\
& \mathrm{Ni}(\mathrm{OH})_{2}+2 \mathrm{CH}_{3} \mathrm{COOCH}_{3}+4 \mathrm{H}_{2} \mathrm{O}
\end{aligned}
$$

Since to improve crystallinity and remove hydroxide phase, films were annealed for $1 \mathrm{~h}$ pure $\mathrm{NiO}$ film is formed after air annealing by following mechanism:

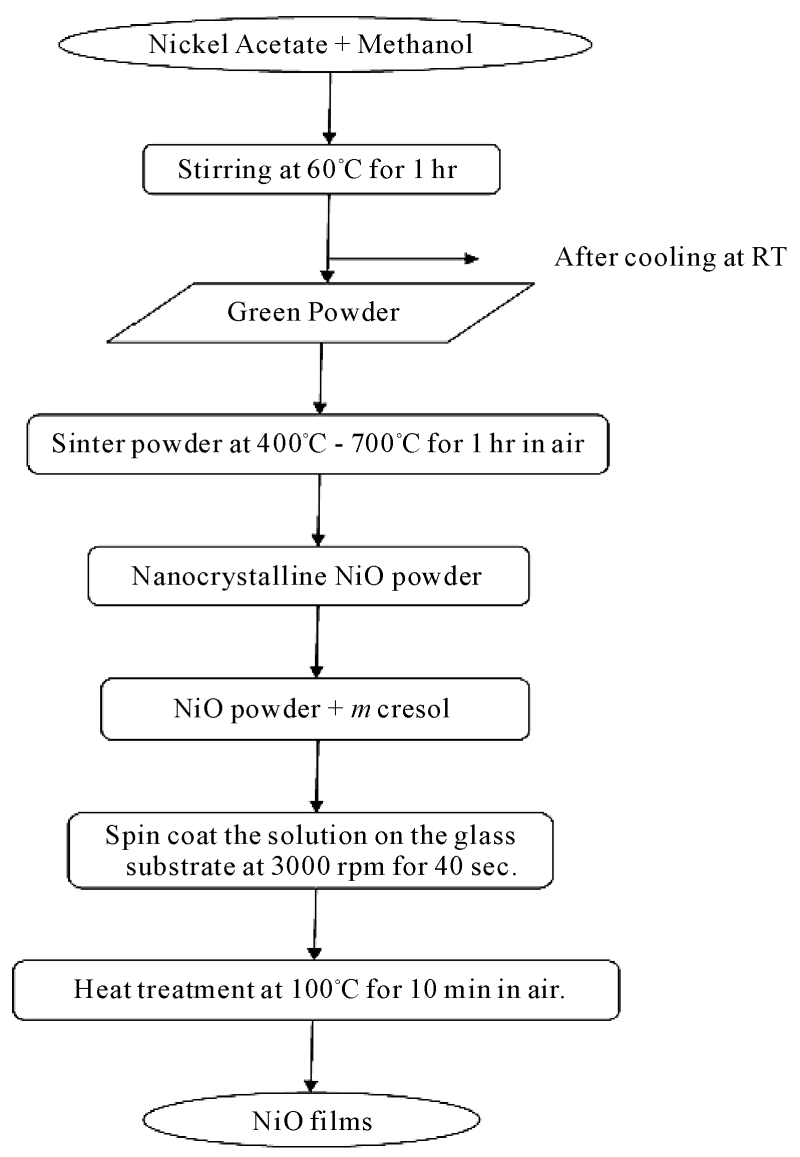

Figure 1. Flow diagram for NiO films prepared from the sol-gel process using the spin-coating method.

$$
\begin{aligned}
& \mathrm{Ni}(\mathrm{OH})_{2} \downarrow+\text { Carbonaceous compounds } \\
& \underset{\text { Air annealing }}{\text { Oxidation }} \mathrm{NiO}+\mathrm{H}_{2} \mathrm{O} \uparrow
\end{aligned}
$$

Thickness was calculated by weight difference method using formula:

$$
t=m / A \rho
$$

where $t$ is film thickness of the film; $m$ is actual mass deposited onto substrate; $A$ is area of the film and is the density of nickel oxide $\left(6.67 \mathrm{~g} / \mathrm{cc}^{2}\right)$.

It was observed that increasing the annealing temperature resulted in a decrease in film thickness from 0.9061 $\mu \mathrm{m}\left(400^{\circ} \mathrm{C}\right.$ annealing) to $0.4997 \mu \mathrm{m}\left(700^{\circ} \mathrm{C}\right.$ annealing). The NiO thin film thickness is also confirmed by using Dektak profilometer and is presented in Table $\mathbf{1}$.

\subsection{Structural Analysis}

Structural analysis of the $\mathrm{NiO}$ films annealed at $400^{\circ} \mathrm{C}$ $700^{\circ} \mathrm{C}$ was carried out by using $\mathrm{CuK}_{\alpha}$ radiation source of wavelength $\left(\lambda=1.54056 \mathrm{~A}^{\circ}\right)$ and the diffraction patterns of films were recorded by varying diffraction angle (20) in the range $20^{\circ}-80^{\circ}$. Figure 2 shows XRD pattern for 
Table 1. Effect of annealing on NiO thin film properties.

\begin{tabular}{|c|c|c|c|c|c|c|}
\hline \multirow{2}{*}{ Sr. No. } & \multirow{2}{*}{ Annealing temperature ${ }^{\circ} \mathrm{C}$} & \multirow{2}{*}{ Crystallite size nm } & \multirow{2}{*}{ Thickness $\mu \mathrm{m}$} & \multirow{2}{*}{ Energy gap $E_{g}, \mathrm{eV}$} & \multicolumn{2}{|c|}{ Activation energy, $E_{a \sigma} e V$} \\
\hline & & & & & HT & $\mathbf{L T}$ \\
\hline 1 & 400 & 41.55 & 0.9061 & 3.86 & 0.110 & 0.082 \\
\hline 2 & 500 & 43.20 & 0.7414 & 3.69 & 0.236 & 0.086 \\
\hline 3 & 600 & 46.80 & 0.6425 & 3.60 & 0.344 & 0.096 \\
\hline 4 & 700 & 50.67 & 0.4997 & 3.47 & 0.481 & 0.143 \\
\hline
\end{tabular}

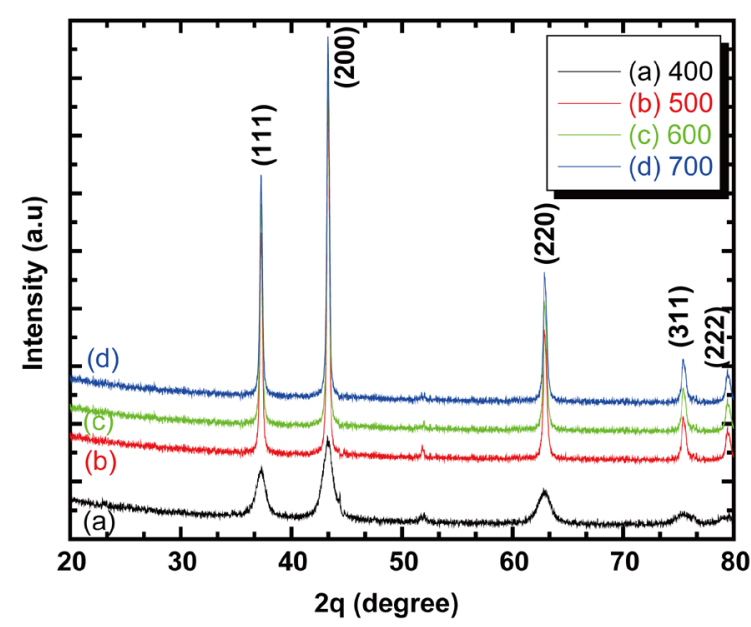

Figure 2. X-ray diffraction patterns of NiO film at different annealing temperatures.

the $\mathrm{NiO}$ films annealed at $400-700^{\circ} \mathrm{C}$. The observed ' $\mathrm{d}$ ' values are in good agreement with standard ' $\mathrm{d}$ ' values and the diffraction peaks are indexed to the cubic phase of $\mathrm{NiO}$ with $\mathrm{a}=\mathrm{b}=\mathrm{c}=4.1678 \mathrm{~A}^{\circ}$ [Joint Committee on Powder Diffraction Standards (JCPDS) No. 73-1519]. It shows well-defined peaks having orientations in the (1 1 1), (2 0 0), (2 20 0), (3 11 1) and (222) planes. The absence of impurity peaks suggests the high purity of the nickel oxide. Compared with those of the bulk counterpart, the peaks are relatively broadened, which further indicates that the deposited material has a very small crystallite size [17]. The crystallite size (D) is calculated using equation as follows [18]:

$$
D=0.9 \lambda / \beta \cos \theta
$$

where, $\beta$ is the half width of diffraction peak measured in radians. The calculation of crystallite size from XRD is a quantitative approach which is widely accepted and used in scientific community [19-22]. The average crystallite size is increased with increasing annealing temperature revealing a fine nanocrystalline grain structure (Table 1).

\subsection{Surface Morphological Studies}

The two-dimensional high magnification surface mor- phologies of $\mathrm{NiO}$ thin films annealed at $400^{\circ} \mathrm{C}-700^{\circ} \mathrm{C}$ were carried out using SEM images are shown in Figure 3(a-d). From the micrographs, it is seen that the film consists of nanocrystalline grains with uniform coverage of the substrate surface with randomly oriented morphology and the crystallite size is increased from 40 - 52 $\mathrm{nm}$ as annealing temperature increases from $400^{\circ} \mathrm{C}$ $700^{\circ} \mathrm{C}$. The crystallite size calculated from SEM analysis is quite in good agreement with that of crystallite size calculated from XRD analysis. Similar results are also observed by Patil et al. [22] for sol gel derived $\mathrm{TiO}_{2}$ films.

\subsection{Electrical Transport Properties}

\subsubsection{Electrical Conductivity Measurement}

The four-probe technique of dark electrical conductivity measurement was used to study the variation of electrical conductivity of film with annealing temperature. The variation of $\log \sigma$ with reciprocal temperature (1000/T) is depicted in Figure 4. After annealing, room temperature electrical conductivity was increased from $10^{-4}$ to $10^{-2}$ $(\Omega \cdot \mathrm{cm})^{-1}$, due to increase in the crystallite size and reduced scattering at the grain boundary. Similar type of increase in electrical conductivity has been observed by Patil et al. [22]. From Figure 4 it is observed that the conductivity of film is increases with increase in annealing temperature, further it is observed that conductivity obeys Arrhenius behavior indicating a semiconducting transport behavior. The activation energies were calculated using the relation:

$$
\sigma=\sigma_{o} \exp \left(-E_{a} / k T\right)
$$

where, $\sigma$ is the conductivity at temperature $T, \sigma_{o}$ is a constant, $k$ is the Boltzmann constant, $T$ is the absolute temperature and $E_{a}$ is the activation energy. The activation energy represents the location of trap levels below the conduction band. From Figure 4, activation energy (HT) was increases from $0.110 \mathrm{eV}$, to $0.481 \mathrm{eV}$, when film annealed from $400^{\circ} \mathrm{C}-700^{\circ} \mathrm{C}$ indicating no significant change.

\subsubsection{Thermo-emf Measurement}

The dependence of thermo-emf on temperature is de- 

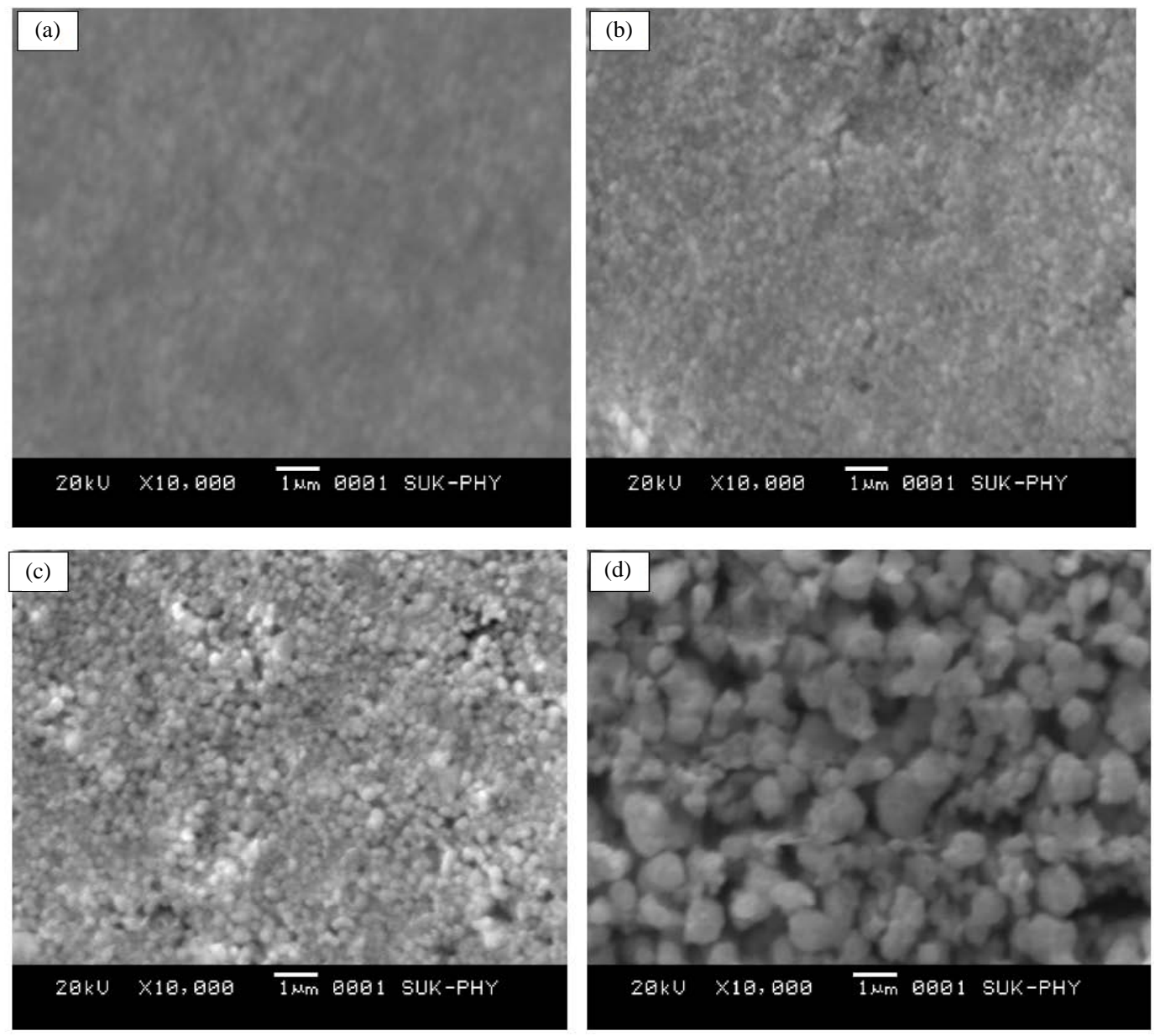

Figure 3. SEM of $\mathrm{NiO}$ thin films anneled at (a) $400^{\circ} \mathrm{C}$; (b) $500^{\circ} \mathrm{C}$; (c) $600^{\circ} \mathrm{C}$; and (d) $700^{\circ} \mathrm{C}$.

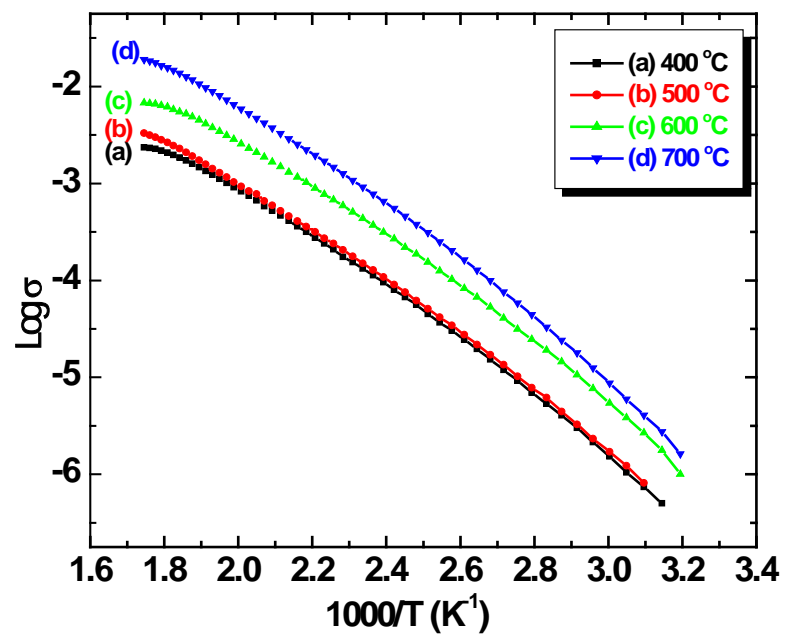

Figure 4. Arrhenius plot of log conductivity vs. 1000/T of $\mathrm{NiO}$ thin film annealed at different temperatures.

picted in Figure 5. The thermo-emf was measured as a function of temperature in the temperature range 300 -
$500 \mathrm{~K}$. The polarity of the thermo-emf was negative at the hot end with respect to the cold end which confirmed that nickel oxide thin films are of $p$-type semiconducting similar to earlier report [23]. The plot shows increase in thermo-emf with increase in temperature when film annealed from $400^{\circ} \mathrm{C}-700^{\circ} \mathrm{C}$. This is attributed to the increase in hole concentration as the annealing temperature increases and also due to the increase in crystallite size as discussed in section 3.3. The thermoelectric power was found to be of the order of $10^{-3} \mathrm{~V} / \mathrm{K}$ when film annealed from $400^{\circ} \mathrm{C}-700^{\circ} \mathrm{C}$

\subsection{Optical Studies}

The optical absorption spectra in the range of 200 - 1000 $\mathrm{nm}$ for $\mathrm{NiO}$ thin films annealed at $400-700^{\circ} \mathrm{C}$ were carried out at room temperature without taking in account of scattering and reflection. Figure 6 shows the optical absorption spectra of $\mathrm{NiO}$ thin films annealed at $400^{\circ} \mathrm{C}$ $700^{\circ} \mathrm{C}$, it is observed that the absorption coefficient is very low for photon energy in the IR and visible region while the sudden increase in the absorption coefficient 


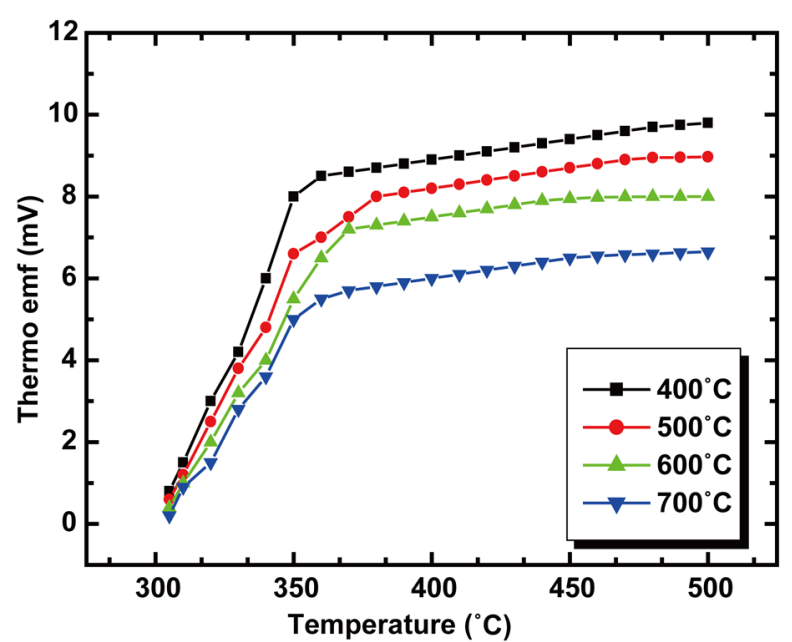

Figure 5. The variation of thermo-emf with temperature for of $\mathrm{NiO}$ thin film annealed at different temperatures.

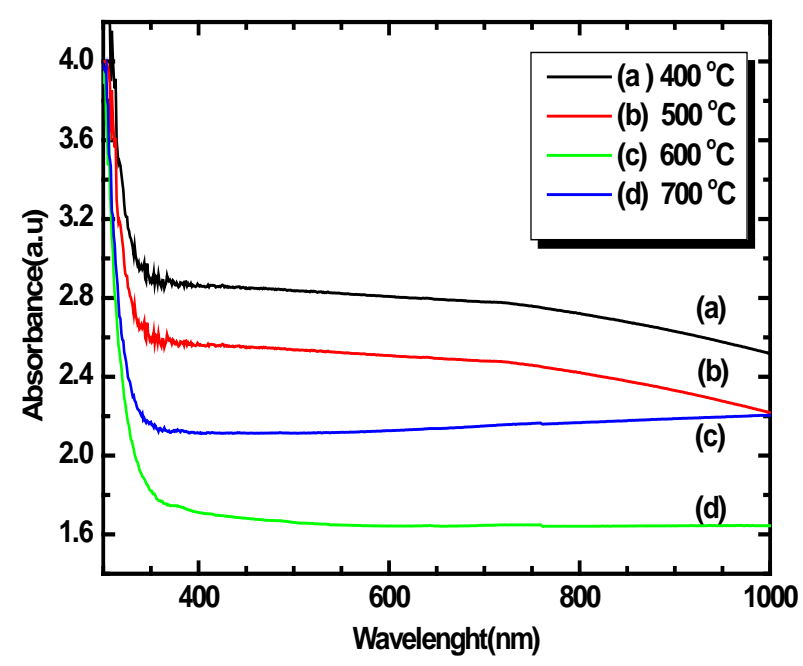

Figure 6. Variation of absorbance $(\alpha t)$ with wavelength $(\lambda)$ of $\mathrm{NiO}$ thin film annealed at different temperatures.

occurs in the near UV region. It was found that, the absorption coefficient of films is increases with increase in annealing temperature. This could be because of increase in the density of states of holes with increase in annealing temperature, similar results are reported by Varkey et al. [24] and Pejova [25]. The optical band gap $\left(\mathrm{E}_{\mathrm{g}}\right)$ of $\mathrm{NiO}$ thin films annealed at $400^{\circ} \mathrm{C}-700^{\circ} \mathrm{C}$ is calculated on the basis of optical absorption spectra using the following equation:

$$
\alpha=\frac{A(E g-h v)^{n}}{h v}
$$

where ' $A$ ' is a constant, ' $E_{g}$ ' is the semiconductor band gap and ' $n$ ' is a number equal to $1 / 2$ for direct gap and 2 for indirect gap compound.

The plots of $(\alpha \cdot h v)^{2}$ versus $h v$ of films annealed at $400^{\circ} \mathrm{C}-700^{\circ} \mathrm{C}$ are shown in Figure 7.

Figure 7 Plot of $(\alpha \cdot h v)^{2}$ versus $(h v)$ of $\mathrm{NiO}$ thin film for different annealing temperatures.

Since the plots are almost linear, the direct nature of the optical transition in $\beta-\mathrm{Ni}(\mathrm{OH})_{2}$ and $\mathrm{NiO}$ is confirmed. Extrapolation of these curves to photon energy axis reveals the band gaps. The band gap was found to be decreased from 3.86 to $3.47 \mathrm{eV}$ for films annealed at $400^{\circ} \mathrm{C}$ $700^{\circ} \mathrm{C}$. Varkey and Fort [14] reported the slightly lower band gaps 3.75 and $3.25 \mathrm{eV}$ for as-prepared $\mathrm{NiOOH}$ and annealed $\mathrm{NiO}$ thin films [24]. The decrease in $E_{g}$ with annealing temperature could be due to increase in crystalline size and reduction of defect sites. This is in good agreement with the experimental results of XRD analysis. According to XRD results, the mean grain size has increased with increased annealing temperature. As the grain size has increased, the grain boundary density of a film decreased, subsequently, the scattering of carriers at grain boundaries has decreased [25].A continuous increase of optical constants and also the shift in absorption edge to a higher wavelength with increasing annealing temperature may be attributed to increase in the particle size of the crystallites along with reduction in porosity.

The decrease in optical band gap energy is generally observed in the annealed direct-transition-type semiconductor films. Hong et al. [26] observed a shift in optical band gap of $\mathrm{ZnO}$ thin films from $3 \cdot 31$ - $3.26 \mathrm{eV}$ after annealing, and attributed this shift to the increase of the $\mathrm{ZnO}$ grain size. Chaparro et al. [27] ascribed this 'red shift' in the energy gap, $E_{g}$, to an increase in crystallite size for the annealed ZnSe films. Bao and Yao [28] also

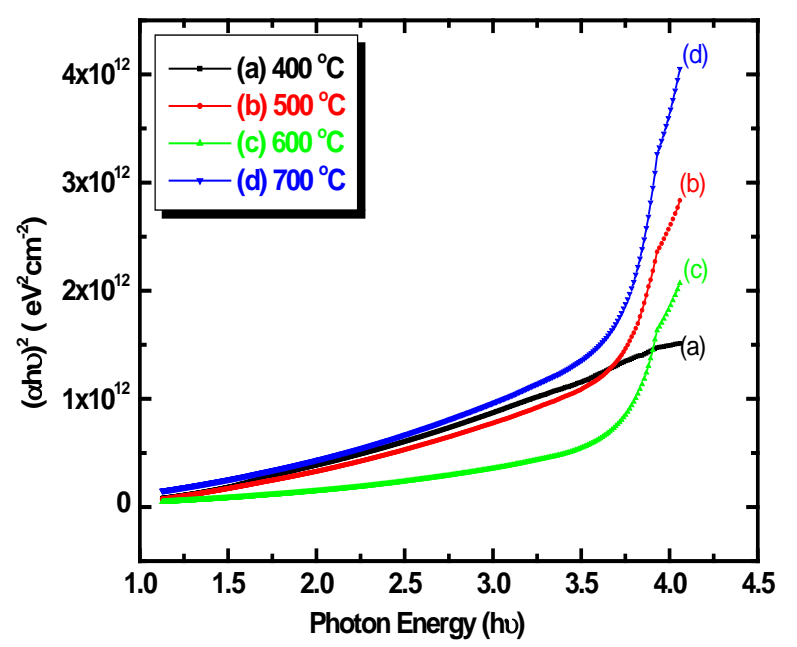

Figure 7. Plot of $(\alpha \cdot h v)^{2}$ versus $(h v)$ of NiO thin film for different annealing temperatures. 
reported a decrease in $E_{g}$ with increasing annealing temperature for $\mathrm{SrTiO}_{3}$ thin films, and suggested that a shift of the energy gap was mainly due to both the quantumsize effect and the existence of an amorphous phase in thin films. In present case, the mean crystallite size increases from 40 to $70 \mathrm{~nm}$ after annealing from $400^{\circ} \mathrm{C}$ $700^{\circ} \mathrm{C}$. Moreover, it is understood that the amorphous phase is reduced with increasing annealing temperature, since more energy is supplied for crystallite growth, thus resulting in an improvement in crystallinity of $\mathrm{NiO}$ films. Therefore, it is believed that both the increase in crystallite size and the reduction in amorphous phase cause are decreasing in band gap of annealed $\mathrm{NiO}$ films. The change in optical band gap energy, $E_{g}$, reveals the impact of annealing on optical properties of the NiO films.

\section{Conclusions}

Nanocrystalline nickel oxide thin films were prepared by low-cost sol gel spin coating technique. The $\mathrm{NiO}$ films were annealed for various temperatures between 400 to $700^{\circ} \mathrm{C}$. The XRD results revealed that the NiO thin film has a good nanocrystalline cubic structure. The SEM results depict that a uniform surface morphology and the nanoparticles are fine with an average grain size of about $40-60 \mathrm{~nm}$. The dc electrical conductivity is increased from $10^{-4}$ to $10^{-2}(\Omega \mathrm{cm})^{-1}$ for films annealed at $400^{\circ} \mathrm{C}$ $700^{\circ} \mathrm{C}$. Optical absorption studies show low-absorbance in IR and visible region with band gap $3.86 \mathrm{eV}$ (at $400^{\circ} \mathrm{C}$ ) which was decreased to $3.47 \mathrm{eV}\left(\right.$ at $700^{\circ} \mathrm{C}$ ). This has been attributed to the decrease in defect levels. The $p$-type electrical conductivity is confirmed from thermoemf measurement with no appreciable change in thermoelectric power after annealing

\section{Acknowledgments}

Authors (VBP) are grateful to DAE-BRNS, for financial support through the scheme no.2010/37P/45/BRNS/1442. Thanks are also extended to Dr.P.S.Patil, Department of Physics, Shivaji University, Kolhapur for providing SEM facility.

\section{REFERENCES}

[1] C. L. Shao, X. H. Yang, H. Y. Guan, Y. C. Liu and J. Gong, "Electrospun Nanofibers of NiO/ZnO Composite," Inorganic Chemistry Communications, Vol. 7, No. 5, 2004, pp. 625-627. doi:10.1016/j.inoche.2004.03.006

[2] G.-J. Li, X.-X. Huang, Y. Shi and J.-K. Guo, "Preparation and Characteristics of Nanocrystalline $\mathrm{NiO}$ by Organic Solvent Method," Materials Letters, Vol. 51, No. 4, 2001, pp. 325-330. doi:10.1016/S0167-577X(01)00312-3

[3] B. Sasi, K. Gopchandran, P. Manoj, P. Koshy, P. Rao and V. K. Vaidyan, "Preparation of Transparent and Semiconducting NiO Films,” Vacuum, Vol. 68, No. 2, 2003, pp. 149-154. doi:10.1016/S0042-207X(02)00299-3

[4] J. D. Desai, S. K. Min, K. D. Jung and O. S. Joo, "Spray Pyrolytic Synthesis of Large Area $\mathrm{NiO}_{\mathrm{x}}$ Thin Films from Aqueous Nickel Acetate Solutions," Applied Surface Science, Vol. 253, No. 4, 2006, pp.1781-1786. doi:10.1016/j.apsusc.2006.03.009

[5] J.-K. Kang, S. W. Rhee, "Chemical Vapor Deposition of Nickel Oxide Films from $\mathrm{Ni}\left(\mathrm{C}_{5} \mathrm{H}_{5}\right)_{2} / \mathrm{O}_{2}$," Thin Solid Films, Vol. 391, No. 2, 2001, pp. 57-61. doi:10.1016/S0040-6090(01)00962-2

[6] K. Nakaoka, J. Ueyama, K. Ogura, "Semiconductor and Electrochromic Properties of Electrochemically Deposited Nickel Oxide Films," Journal of Electroanalytical Chemistry, Vol. 571, No. 1, 2004, pp. 93-99. doi:10.1016/j.jelechem.2004.05.003

[7] D. J. Taylor, P. F. Fleig, S. T. Schwab and R. A. Page, "Sol-Gel Derived Nanostructured Oxide Lubricant Coatings,” Surface and Coatings Technology, Vol. 120, 1999, pp. 465-469. doi:10.1016/S0257-8972(99)00418-1

[8] J. L. Garcia-Miquel, Q. Zhang, S. J. Allen, A. Rougier, A. Blyr, H. O. Davies, A. C. Jones, T. J. Leedham, P. A.William and S. A. Impey, "Nickel Oxide Sol-Gel Films from Nickel Diacetate for Electrochromic Applications,” Thin Solid Films, Vol. 424, No. 2, 2003, pp.165-170. doi:10.1016/S0040-6090(02)01041-6

[9] J. W. Park, J. W. Park, D. Y. Kim, J. K. Lee, "Reproducible Resistive Switching in Nonstoichiometric Nickel Oxide Films Grown by rf Reactive Sputtering for Resistive Random Access Memory Applications,” Journal of Vacuum Science and Technology A, Vol. 23, No. 5, 2005, pp.1309-1313. doi:10.1116/1.1953687

[10] K. S. Ahn, Y. C. Nah and Y. E. Sung, "Surface Morphological, Microstructural, and Electrochromic Properties of Short-Range Ordered and Crystalline Nickel Oxide Thin Films”, Applied Surface Science, Vol. 199, No. 1-4, 2002, pp. 259-269. doi:10.1016/S0169-4332(02)00863-2

[11] H. L. Chen, Y. M. Lu and W. S. Hwang, "Thickness Dependence of Electrical and Optical Properties of Sputtered Nickel Oxide Films,” Thin Solid Films, Vol. 514, No. 1-2, 2005, pp. 361-365. doi:10.1016/j.tsf.2006.04.041

[12] P. Pramanik, S. Bhattacharya, "A Chemical Method for the Deposition of Nickel Oxide Thin Films," Journal of Electrochemical Society, Vol. 137, No. 12, 1990, pp. 3869-3870. doi:10.1149/1.2086316

[13] B. Pejova, T. Kocareva, M. Najdoski and I. Grozdanov, "A Solution Growth Route to Nanocrystalline Nickel Oxide Thin Films,” Applied Surface Science, Vol. 165, No. 4, 2000, pp. 271-278. doi:10.1016/S0169-4332(00)00377-9

[14] A. J. Varkey and A. F. Fort, "Solution Growth Technique for Deposition of Nickel Oxide Thin Films," Thin Solid Films, Vol. 235, No. 1-2, 1993, pp. 47-50. doi:10.1016/0040-6090(93)90241-G

[15] S. Y. Han, D. H. Lee, Y. J. Chang, S. O. Ryu and T. J. Lee, C. H. Chang, "The Growth Mechanism of Nickel Oxide Thin Films by Room-Temperature Chemical Bath Deposition," Journal of Electrochemical Society, Vol. 
153, No. 6, 2006, pp. C382-C386. doi:10.1149/1.2186767

[16] S. Banerjee, A. Santhanam, A. Dhathathrenyan and M. Rao, "Synthesis of Ordered Hexagonal Mesostructured Nickel Oxide,” Langmuir, Vol. 19, No. 13, 2003, pp. 5522-5525. doi:10.1021/la034420o

[17] E. Comini, G. Faglia, G. Sberveglieri, Z. Pan and Z. L. Wang, "Stable and Highly Sensitive Gas Sensors Based On Semiconducting Oxide Nanobelts," Applied Physics Letters, Vol. 81, 2002, pp.1869-1871. doi:10.1063/1.1504867

[18] A. Studenikin, N. Golego and M. Cocivera, "Fabrication of Green and Orange Photoluminescent, Undoped ZnO Films Using Spray Pyrolysis,” Journal of Applied Physics, Vol. 84, No. 4, 1998, pp. 2287-2280. doi:10.1063/1.368295

[19] P. K. Ghosh, R. Maity, K. K. Chattopadhyay, "Electrical and Optical Properties of Highly Conducting CdO: F Thin Film Deposited by Sol-Gel Dip Coating Technique,” Solar Energy Materials and Solar Cells, Vol. 81, No. 2, 2004, pp. 279-289. doi:10.1016/j.solmat.2003.11.021

[20] K. Gurumurugan, D. Mangalaraj, S. K. Narayandass and Y. Nakanishi, "DC Reactive Magnetron Sputtered CdO Thin Films,” Materials Letters, Vol. 28, No. 4-6, 1996, pp. 307-312. doi:10.1016/0167-577X(96)00074-2

[21] C. N. R. Rao, S. R. C. Vivekchand, K. Biswas and A. Govindaraj, "Synthesis of Inorganic Nanomaterials," Dalton Transactions, Vol. 34, 2007, pp. 3728-3749. doi:10.1039/b708342d

[22] S. G. Pawar, S. L. Patil, M. A. Chougule and V. B. Patil, "Synthesis and Characterization of Nanocrystalline $\mathrm{TiO}_{2}$ Thin Films," Journal of Materials Science: Material in
Electronics, Vol. 22, No. 3, 2011, pp.260-264. doi:10.1007/s10854-010-0125-8

[23] Y. K. Jeong and G. M. Choi, "Nonstoichiometry and Electrical Conduction of CuO," Journal of Physics and Chemistry of Solids, Vol. 57, No. 1, 1996, pp. 81-84. doi:10.1016/0022-3697(95)00130-1

[24] B. Pejova, T. Kocareva, M. Najdoski and I. Grozdanov, "A Solution Growth Route to Nanocrystalline Nickel Oxide Thin Films,” Applied Surface Science, Vol. 165, No. 4, 2000, pp. 271-278. doi:10.1016/S0169-4332(00)00377-9

[25] J. H .Lee, K. H. Ko and B. O. Park, "Electrical and Optical Properties of ZnO Transparent Conducting Films by the sol-gel method,” Journal of Crystal Growth, Vol. 247, No.1-2, 2003, pp. 119-125. doi:10.1016/S0022-0248(02)01907-3

[26] R. Hong, J. Huang, H. He, Z. Fan and Shao "Influence of Different Post-Treatments on the Structure and Optical Properties of Zinc Oxide Thin Films," Applied Surface Science, Vol. 242, No. 3-4, 2005, pp. 346-352. doi:10.1016/j.apsusc.2004.08.037

[27] A. M. Chaparro, M. A. Martinez, C. Guillen, R. Bayon, M. T. Gutierrez and J. Herrero, " $\mathrm{SnO}_{2}$ Substrate Effects on the Morphology and Composition of Chemical Bath Deposited ZnSe Thin Films,” Thin Solid Films, Vol. 361, 2000, pp.177-182. doi:10.1016/S0040-6090(99)00791-9

[28] D. H. Bao and X. Yao, Naoki Wakiya, Kazuo Shinozaki' and Nobuyasu Mizutani, "Band-Gap Energies of Sol-Gel Derived $\mathrm{SrTiO}_{3}$ thin films" Applied Physics Letters, Vol. 79, No. 23, 2001, pp. 3767-3772. doi:10.1063/1.1423788 